Why a cyclitis did not supervene is also a matter for comment. The unusual development of a separation of the lamellae of the cornea is sufficiently rare to afford considerable discussion. The result following an original method of surgery was highly gratifying to the surgeon, but the fact that there was a physiological variation in the vision of the unoperated as well as the operated eye must not be overlooked. There was likewise a degree of spontaneous absorption of the steamy area in the cornea of the unoperated eye.

\title{
A CASE OF SYMPATHETIC OPHTHALMITIS
}

BY

\section{GEORGE YOUNG \\ COLCHESTER}

HERETOFORE ophthalmic surgeons have opposed the enucleation of the first eye, once the second has become affected by sympathetic ophthalmitis, if any degree of vision remains in the first eye. Experience derived from tragic lessons in the past had established this rule. The latest books of reference quote it. More recent summaries remind us of it again.(1) But when the slit-lamp enabled us to recognize much more recent signs in the second eye than had been possible previously, enthusiasm voiced the notion that it might be advisable to enucleate the first eye as soon as we saw those signs. On such occasions my mind rose in rebellion, for I believed in the old rule so firmly as to fancy that if the slit-lamp were to lead us into even considering such a step it were better to be on guard against actually taking it. Moreover, now that we could detect the very first signs in the second eye, we should be sooner warned; while had we failed to recognize these initial signs we might have removed the first eye judging the second to be still within the period of safety from sympathetic ophthalmitis.

Then this case came along. Perhaps to remind me that tempora mutantur. Its course gives food for reflection; and though it does not presume to overthrow, yet it challenges the old maxim. For it might actually prove correct to remove the first eye, vision or no vision, even after the earliest signs have appeared in the second eye.

T.H., aged 72 years, a ship's stoker, had a lubricating gauge glass burst and cut his left eye through the cornea and ciliary body in the upper outer quadrant on August 6, 1926. He was under the care of Mr. J. A. Valentine at the Portsmouth Eye Hospital till the end of August, when he returned home and presented himself at the Out-patient Department of the Essex County Hospital with a letter from my colleague asking me 
to carry on with his case. The eye was under atropine and was apparently quieting down. In particular it was free from plastic exudates and keratitis punctata, and the aqueous humour was clear. It showed an excised prolapse and adherent scar. The other eye was normal. Both eyes were scrutinized with the slitlamp on every clinical day and on September 29, 1926, keratitis punctata was observed in the wounded left eye, with oblique illumination. The right eye was free from ciliary injection and oblique illumination showed nothing, but the slit-lamp did : there was no increased flare, but at the temporal margin of the pupil there was the minutest beginning of exudation from the edge of the iris and the posterior surface of the cornea showed several small deposits, like droplets of liquid glue, transparent but with a tinge of buff.

I was conscious of being face to face with an entirely new clinical aspect, which more than shook the firmness of my previous conviction. Thrown on one's own resources with no time to lose means acting promptly and with decision. This was no case for obstinately adhering to a principle, where reason dictated otherwise. Here were the "pellucid keratic precipitates" so emphatically pointed out as quite distinct from organized keratitis punctata, and from "bedewing." The left eye, already seriously impaired, had now flared up and was commencing its attack on its opponent, itself condemned to perhaps complete destruction, its vision reduced to hand movements. But the second eye was barely attacked. I felt that the second eye would be doomed unless I sacrificed the first without delay. The man was intelligent. I put the case before him in all its colours and he decided to take a fighting chance and face the possibility of total blindness.

Inside of three hours the left eye was enucleated and with it a long piece of optic nerve was excised. On principle! For what conclusive evidence have we that infection travels through the optic nerve?

My house surgeon-Mr. Joy Smith-at once started vigorous therapy.* This treatment was continued by him most faithfully for ten weeks, during which the patient went through an acute attack of sympathetic ophthalmitis, with vision at one time dropping below $6 / 60$, and all the inflammatory signs, the haze of fundus and media, the blurring of optic nerve, called optic neuritis without sufficient evidence. It was significant that the anterior portion of the eye escaped plastic exudates, and the aqueous humour was far less turbid than is usual, only showing increased flare when the eye was at its worst. The eye made a

* Iodides and salicylates in large steady doses, and salvarsan intravenous injections frequently repeated. Tetanus seemed too heroic a remedy until we know more about it. 
complete recovery. On January 17,1927 , his vision was $6 / 9$ partly under atropine $\bar{c}$. $+0.50 \mathrm{sph} .+0.25 \mathrm{cyl}$. horiz. $=6 / 9$ better. On March 22, 1927, it was exactly the same, when atropine was stopped and has not been resumed. The eye has been quiet up to the present but for occasional attacks of conjunctivitis to which he is subject, partly due to a tendency to ectropion, which clear up promptly under lotion and eye drops.

My last examination was on August 31, 1927 : conjunctiva clean, fundus and media flawless, with ophthalmoscope and slit-lamp. even lacking the tell-tale landmarks on the lens capsule which stand so often as the life-long recorders of bygone uveitis. Keratometer : scant $0.50 \mathrm{D}$. against at $180^{\circ}$. V. $6 / 9$ partly $\overline{\mathrm{c}}_{\mathrm{c}}-0.75 \mathrm{cyl}$. $90^{\circ} 6 / 9$ full ; $\bar{c}$. +3.50 J.3. As this is one year and twenty-five days after the accident $I$ think it is reasonable to look upon his cure as permanent.*

Sympathetic ophthalmitis has been a rare occurrence in my experience and I cannot offer clinical statistics of great value, nor does this single case answer my questions. How much of its recovery was due to prompt surgery? How much to therapy? It is significant that this is my first and only case that has made anything like as good a recovery, though in all others equal efforts were made with therapeutic measures. With all due respect for other views and with every aversion against too hasty conclusions. I am inclined to attribute this recovery to the early removal of the first eye, and to believe that had I not removed it this patient would not be blessed to-day with one quite sound eye. Let all who have similar experiences to tell come forth with them, and if this should prove in time to be the rule we may well credit the slit-lamp with having drawn some of the teeth of this dreaded dragon, and if progress should lead to the overthrow of the old doctrine the latter may be found to have been no less sound in its time.

I cannot close my paper without acknowledging the debt of gratitude, which I for one owe to Mr. T. Harrison Butler and the teaching in his slit-lamp course. Through force of circumstance I could not go to the source at my old university at Zürich. The regret I felt at this he has banished, for he brought it to me and I learned of "pellucid keratic precipitates" and "bedewing," terms I believe suggested by himself. I owe my having "spotted" this case in time to his teaching. There is no doubt that my fortunate decision here was prompted by some strong opinions he expressed at times. ${ }^{(2)}$

Little dots of glue on slides, viewed against a darker background, as would be the keratitis punctata pellucida against iris or pupil by ordinary oblique examination, are quite invisible and would escape the most careful observer. Placed on a white surface, or viewed

* The eye is still in perfect condition. January, 1928. 
through a No. 3 ocular layer inverted on the side, as taught by Stoehr in his practical book of histology, they give a fair idea of what the deposits looked like, which I saw on the back of the cornea. With the slit-lamp and high power and the judicious use of illuminations they were seen easily, as was also their tinge of buff.

I am indebted to Mr. Valentine for kindly furnishing me with what notes and sketches he possessed of this case while the man was under his care. He first came to him on August 13, 1926, one week after the accident. The iris was prolapsed, vision on August 20 was fingers. On August 21 the prolapse was excised and the hole covered with conjunctiva, fastened with two stitches. The lower lid was cauterized in six places on its conjunctival surface for ectropion.

No one desires more than I do that the true credit in this case be given to the true cause. My scepticism of the value of therapeutic remedies in this disease inclines me to attribute it so entirely to surgery, that in a similar case I would feel like eliminating them, were it not for the blood condition, which has been put clearly before us. ${ }^{(3)}$ In the face of such convincing evidence one does not feel justified in suspending the additional therapeutic measures. But admitted we must combat them : are these blood conditions pathognomonic of sympathetic ophthalmitis? I shall not feel they are, until similar blood changes have been positively excluded in all other forms of uveitis. And this is a point for investigation for those who are in a position to carry it out.

\section{REFERENCES}

1. Hepburn, Malcolm.-Trans. Ophthal. Soc. U.K., Vol.XLVI, p. 244. par. 4.

2. Butler, T. Harrison.-Trans. Ophthal. Soc. U.K., Vol. XLVI, p. 261.

3. Browning, S. H.-Trans. Ophthal. Soc. U.K., Vol. XLVI, p. 249.

\section{A NEW OPERATING LOUPE}

BY

\section{I). Priestley Smith}

BIRMINGHAM

Magnification is a decided advantage in such minute work as eye-surgery. The best means is a pair of lenses placed at a considerable distance from the wearer's eyes, for to obtain the desired magnification by glasses worn close to the eyes the lenses have to be so strong that one is compelled to get too close to the field of operation. For the best result they must be not much less than $8 \mathrm{~cm}$. from the wearer's cornea.

Another advantage of having them at such a distance from the eyes is that by using lenses of the right size one can magnify 